\title{
PREVALENCE OF GDM IN KHUH, AND ITS EFFECT ON PREGNANCY AND NEONATAL OUTCOME FOLLOWING IADPSG CRITERIA (THE INTERNATIONAL ASSOCIATION OF DIABETES AND PREGNANCY STUDY GROUP).
}

\footnotetext{
1. MCPS, FCPS, FRCOG (UK) Accredited Colposcopist (UK) Consultant Department of Obs \& Gyne King Hamad University Hospital Bahrain.

2. FCPS

Senior Registrar

Department of Obs \& Gyne

King Hamad University Hospital Bahrain.

3. Saudi Board

Resident

Department of Obs \& Gyne

King Hamad University Hospital

Bahrain.

4. MD

Resident

Department of Obs \& Gyne

King Hamad University Hospital

Bahrain.
}

Correspondence Address:

Dr. Samina Anwar

House No.110-E, Street 6,

Phase-5, DHA Lahore.

samina6566@hotmail.com

Article received on:

25/03/2019

Accepted for publication:

$11 / 06 / 2019$

Received after proof reading: $28 / 08 / 2019$

\begin{abstract}
Samina Anwar', Gulmeen ${ }^{2}$, Shareen Sultan ${ }^{3}$, Sara Amin ${ }^{4}$
ABSTRACT... Introduction: GDM is a metabolic disorder defined as its recognition first time in pregnancy. Women with GDM are at increased risk of morbidity and poor fetal outcome. Hence it is essential that early diagnosis and management of disease is carried out to avoid poor maternal and fetal outcome. Objectives: The study was conducted to find out the prevalence of GDM in KHUH following the International Association of Diabetes and Pregnancy Study Groups (IADPSG\} Criteria. Following this strict criteria we analyzed the management and its effect on maternal and fetal outcome. Study Design: Retrospective cohort study. Setting: King Hamad University Hospital. Period: Feb 2015-Jan 2016. Inclusion: Patients diagnosed as GDM after 75gm OGTT. Exclusion Criteria: Known diabetic. Patients with unknown diabetic status. Materials and Methods: The study included 230 patients mostly between 24-28 weeks attending the antenatal clinic and some in late third trimester. This study included patient with GDM from - Feb 2015-Jan 2016. For the said year the total number of deliveries were 2747. These patients were given $75 \mathrm{gm}$ OGTT test, by taking first fasting levels and then were given $75 \mathrm{gms}$ of glucose drink and blood levels were taken at 1 and $2 \mathrm{hrs}$ respectively. The fasting, $1 \mathrm{hr}$ and $2 \mathrm{hr}$ values were $<5.1,1 \mathrm{hr}<10$ and $2 \mathrm{hrs}<8.5$. Patient with GDM were managed and followed till delivery to find out the maternal and fetal outcome. Results: The prevalence of GDM in this study was $8 \%$. The C-section rate was $21.8 \%$. The antenatal complications were $7.3 \%$ and major complication was hypertension. The postnatal complications were $5.6 \%$ and main complication was post-partum haemorrhage (PPH) due to lacerations. Macrosomia was found in $3.4 \%$ of cases. The preterm delivery rate was $2.6 \%$. NICU admission was $25.7 \%$ and $58.3 \%$ of these were admitted for 24 hour observation only. Conclusion: GDM affects maternal and fetal outcome. By following the IADPSG criteria for screening and managing the women helped us in attaining good maternal and fetal outcome.
\end{abstract}

Key words: $\quad$ GDM, IADPSG, Macrosomnia, Perinatal Morbidity and Mortality.

Article Citation: Anwar S, Gulmeen, Sultan S, Amin S. Prevalence of GDM in KHUH, and its effect on pregnancy and neonatal outcome following IADPSG criteria (the international association of diabetes and pregnancy study group). Professional Med J 2019; 26(9):1491-1499.

DOI: 10.29309/TPMJ/2019.26.09.3442

\section{INTRODUCTION}

Gestational diabetes is glucose intolerance that is diagnosed first time in pregnancy. GDM is a public health problem in Bahraini female population and has short and long term effects on both mother and fetus. As a consequence, various intensified management regimens are used for women with gestational abnormalities of glucose tolerance. The aim is to return glucose control to normal and improve perinatal outcome. This involves an increased level of maternal inconvenience compared with standard antenatal care, usually in the form of more frequent antenatal visits, daily capillary glucose series, early delivery and possibly an increased caesarean section rate. There is some evidence that management aimed at improving glucose control in pregnancy may improve perinatal outcome in women with gestational diabetes.

It has been reported that GDM affects $1-14 \%$ of all pregnancies and its incidence is rising. GDM can lead to perinatal morbidity and mortality as well as maternal morbidity. It is therefore very important 
that such women should be diagnosed and monitored antenatally and a follow up postnatally should be carried out to avoid complications. The complications to mother are hypertension, obesity, induction of labour, operative delivery, perineal trauma, postpartum haemorrhage, blood transfusion and wound infection. The fetus can be of low birth weight, macrosomic, obstructed labour, shoulder dystocia, prematurity, sepsis, congenital malformations, hypoglycemia, admission to NICU and prolonged hospital stay. ${ }^{1}$

The risk factors for GDM are, obesity, positive family history of diabetes, advance maternal age, history of diabetes in previous pregnancy, previous macrosomic infant, and unexplained fetal death. Women with GDM have a higher potential for developing type 2 diabetes in future. A cohort study from Israel examined the effect of intensive management of diet and three protocols for active elective management of route of birth on outcomes in women with gestational diabetes. The study concluded that intensive management of diet and active management of birth were beneficial to women with gestational diabetes and their babies. ${ }^{2}$

One of the study of pregnancy outcome of GDM in King Khalid university hospital Riyadh showed that incidence of GDM was found to be $8.6 \%, 74.6 \%$ was spontaneous vaginal deliveries,21.6\% delivered by lower segment cesarean section, maternal morbidity was $1.2 \%$ and the incidence of neonatal intensive care admission was $4.9 \%{ }^{3}$

In addition to perinatal morbidity the infant of mother with GDM are at increased risk of childhood obesity and early onset type 2 diabetes. This is why WHO is following strict criteria the IADPSG criteria for screening and managing the women helped us in attaining good maternal and fetal outcome. $^{4}$

The aims were;

- To diagnose woman at risk and to avoid maternal and fetal morbidity as well as helping them to delay or avoid type 2 diabetes.

- To find out women with GDM and manage them appropriately antenatally and analyze the management by studying perinatal morbidity and mortality as well as maternal morbidity.

\section{SUBJECTS AND METHODS}

It is a retrospective cohort study conducted among the pregnant women attending the King Hamad University Hospital. As Bahrain is a cosmopolitan country so the hospital population is comprised of different ethnicities, Bahraini, Iranian, Asians, Europeans, Egyptians, Yemenis and few from other GCC countries. This study was conducted over a period of 1 year from February 2015 January 2016. Total number of deliveries for the said year were 2747 . Out of them 272 constituted $10 \%$ of total of deliveries were labeled as having gestational diabetes mellitus, while after reviewing all the patient data 230 cases constituting $8 \%$ fitted the criteria of being diagnosed as having gestational diabetes mellitus.

This study was approved by Research and Education Department at King Hamad University Hospital. Most of the patients involved in this study were booked and screened for GDM using the IADPSG international association of diabetes and pregnancy study group's strict criteria and those who were found positive for GDM were counselled, educated and followed up regularly in pregnancy to avoid the complications. Appointment with dietician and endocrinologist were arranged at appropriate intervals along with follow up in obstetric clinic for maternal and fetal monitoring till delivery to find out maternal and neonatal outcome.

A well designed proforma was used to collect the data. All the patients' records were obtained from the antenatal, labour and delivery ward. Proformas were filled and a statistical analysis was performed using excel sheets. The $P$ values in data have been obtained by running a 2 sample z-test.

\section{RESULTS}

The $p$ values in data have been obtained by running a 2 sample z-test.

From a total of 230 patient in GDM group $20 \%$ 
were on insulin and $80 \%$ were on diet as shown in Table-l. This is because of education, combined care and frequent follow up and admission in case of unsatisfactory control as well as much stress was on lifestyle adjustment. The patient delivered between 37-40 weeks shown in TableII. The patient induced after 39 weeks has low operative incidence than those before as well as number of prostin used as shown in Table No 3 were more in those induced before 39 weeks. The length of stay was also more in group with induction at 38 weeks.

The induction rate was $38 \%$ which is very high with P-value (.0002) and although the rate of total C-section was not high but those induced before 39 weeks $84 \%$ ended in C-section as shown in Table-III. Regarding C-section rate in this group was $25.2 \%$ and by deducting the previous 2 and $3 \mathrm{C}$-section the corrected rate is $21.8 \%$. Most of the patient induced at $38 \mathrm{wks}$ and ended in C-section for fetal distress $18(62 \%)$, for failure to progress, $7(24 \%)$ and failed IOL $2(6 \%)$ which is the end result of the cases if induced earlier. The number of prostin used in 19 patients who ended in C-section were as 6(33\%) received 1 dose, $8(39 \%)$ received 2 doses, $2(11 \%)$ received 3 doses, another $2(11 \%)$ received 4 doses and lastly $1(6 \%)$ received 5 doses. Table-IV showed as age increases the incidence of GDM increases. Antenatal complication as shown in Table-V was only $5.3 \%$ much less but the major one was hypertension and polyhydramnios. Post natal complications were the same as in literature but the incidence was only $5.6 \%$ as shown in TableVI. The length of stay among patients who had induction of labour was $2-3$ days in $58(51 \%)$ of patients, 3-5 days in 22(19.3\%) and more than 5 days in $8(7.04 \%)$. The length of stay was longer in patients induced at or before 38 weeks.

Majority of the babies were average weight. The record of 172 babies which we were able to get showed that $34 \%(60)$ were between 2.5 $3 \mathrm{~kg}, 58 \%(99)$ babies were $3-3.9 \mathrm{~kg}$ and $4-4.4 \mathrm{~kg}$ babies were only $5(3 \%)$. Only 1 baby was $4.5 \mathrm{~kg}$ and the mother of this baby was a late booker as well. This was because of good and early control. Table-VII shows that neonatal morbidities were $25.7 \%$. Among them NICU admission was in $58 \%$ of cases. NICU admission was more as per protocol all the babies whose mothers were on insulin were kept in NICU for $24 \mathrm{hrs}$, however the hypoglycemia was seen only in $8 \%$ of cases. Table-VIII shows that among 2747 total deliveries 230 patients $(8 \%)$ were GDM. The pregnancy outcome in the general and GDM group is shown. Statistically significant differences in pregnancy complications between study patient and control group noted were induction of labour Pvalue (.0002), Preterm delivery $P(.0007)$ and NICU admission $P(.0001)$. Preterm delivery was more in Control group because of different causes but was less in GDM because of better and early control of GDM.

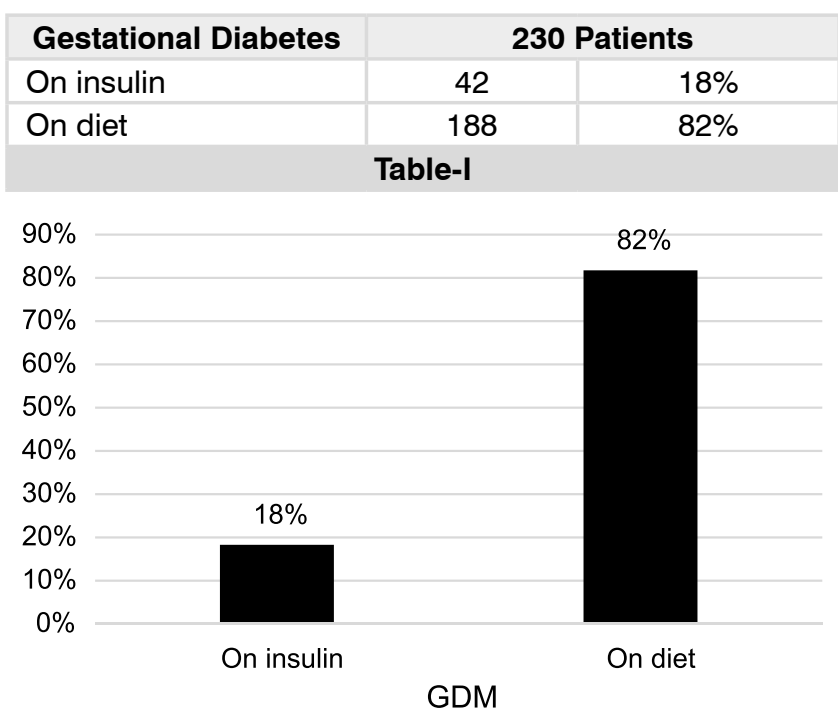

Figure-1

\begin{tabular}{|l|c|c|}
\hline Duration of Gestation - SVD & \multicolumn{2}{|c|}{$\mathbf{1 0 3}$ Patients } \\
\hline$<37$ weeks & 2 & $2 \%$ \\
\hline 37 - 38 weeks & 12 & $11 \%$ \\
\hline 38 - 39 weeks & 55 & $53 \%$ \\
\hline 39 - 40 weeks & 34 & $34 \%$ \\
\hline
\end{tabular}

Table-II

\begin{tabular}{|l|c|c|}
\hline \multicolumn{3}{|c|}{ IOL and Outcome } \\
\hline & No. of Patients & Percentage \\
\hline IOL & 88 & $38 \%$ \\
\hline Vaginal delivery & 69 & $78 \%$ \\
\hline C-section & 19 & $21.5 \%$ \\
\hline $\begin{array}{l}\text { C Section in Patients } \\
<38 \text { weeks }\end{array}$ & 16 & $84 \%$ \\
\hline & Table-III & \\
\hline
\end{tabular}




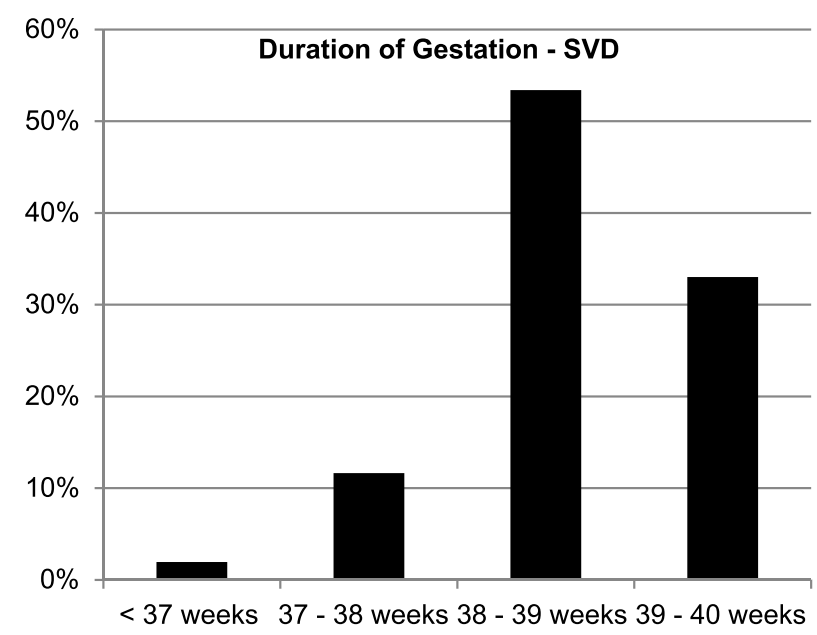

Figure-2

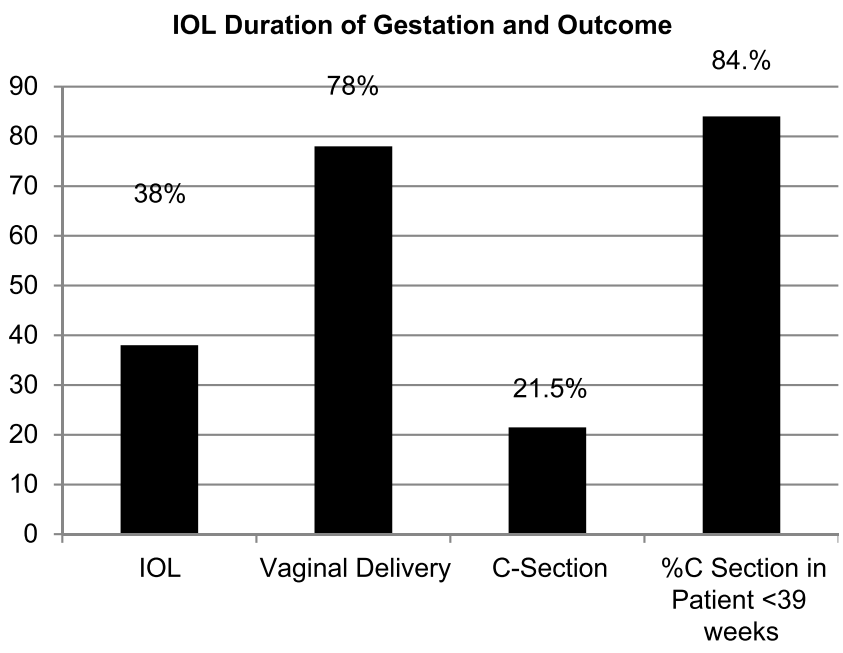

Figure-3

\begin{tabular}{|l|c|c|}
\hline Age of the Patient & \multicolumn{2}{|c|}{230 Patients } \\
\hline $20-30 y r s$ & 110 & $47.8 \%$ \\
\hline $30-40 y r s$ & 100 & $43.4 \%$ \\
\hline >40yrs & 20 & $8.7 \%$ \\
\hline
\end{tabular}

\begin{tabular}{|l|c|c|}
\hline Antenatal Complications & \multicolumn{3}{|c|}{$\mathbf{1 7}$ Patients (7.3 \% ) } \\
\hline PIH & 4 & $24 \%$ \\
\hline PET & 4 & $24 \%$ \\
\hline Obstetric cholestasis & 2 & $12 \%$ \\
\hline Polyhydraminos & 4 & $24 \%$ \\
\hline Oligohydraminos & 1 & $5.3 \%$ \\
\hline Hyperthyroidism & 1 & $5.3 \%$ \\
\hline Heart diseases & 1 & $5.3 \%$ \\
\hline & Table-V & \\
\hline
\end{tabular}

Professional Med J 2019;26(9):1491-1499.

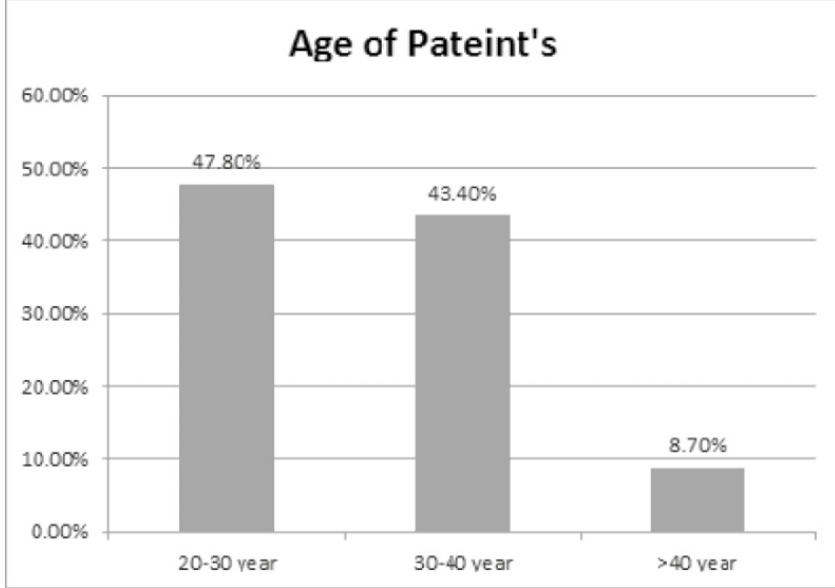

Figure-4

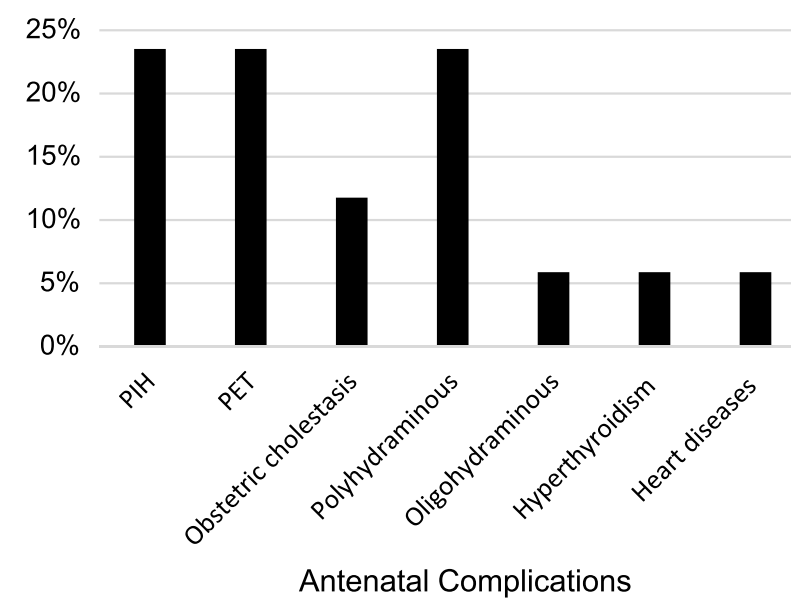

Figure-5

\begin{tabular}{|l|c|c|}
\hline \multicolumn{1}{|c|}{ Postpartum Complications } & $\mathbf{1 3}$ patients (5.6\%) \\
\hline Postpartum hemorrhage & 7 & $54 \%$ \\
\hline Perineal tears sutured under GA & 2 & $15 \%$ \\
\hline Manual removal of placenta & 1 & $8 \%$ \\
\hline Evacuation of hematoma & 1 & $8 \%$ \\
\hline Wound infection & 2 & $15 \%$ \\
\hline
\end{tabular}

Table-VI

\begin{tabular}{|l|c|c|}
\hline Neonatal Morbidities & \multicolumn{2}{|c|}{ 59 Patients } \\
\hline Admission to NICU & 35 & $59.3 \%$ \\
\hline Hypoglycemia & 5 & $8.4 \%$ \\
\hline Pre-term & 6 & $10.1 \%$ \\
\hline Twins & 1 & $1.6 \%$ \\
\hline Meconium & 2 & $3.3 \%$ \\
\hline PROM & 7 & $11.6 \%$ \\
\hline IUGR & 2 & $3.3 \%$ \\
\hline Sever PET & 1 & $1.6 \%$ \\
\hline
\end{tabular}




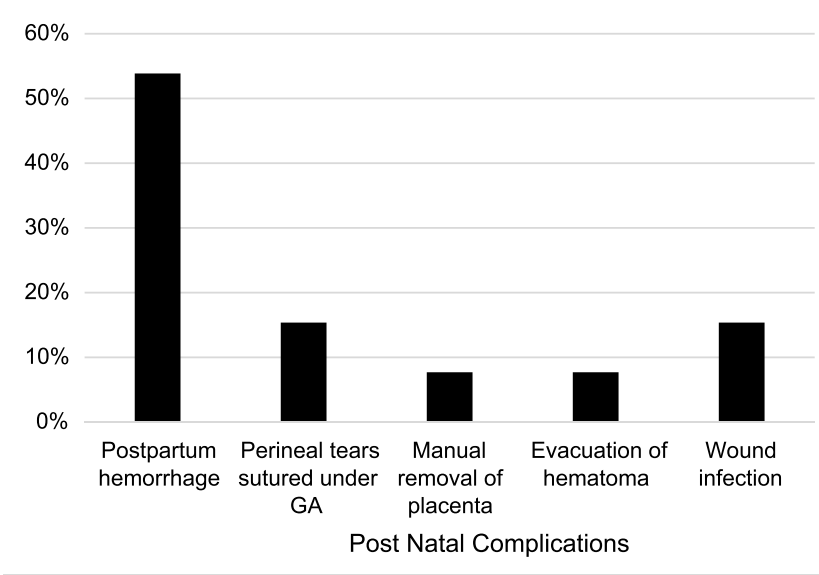

Figure-6

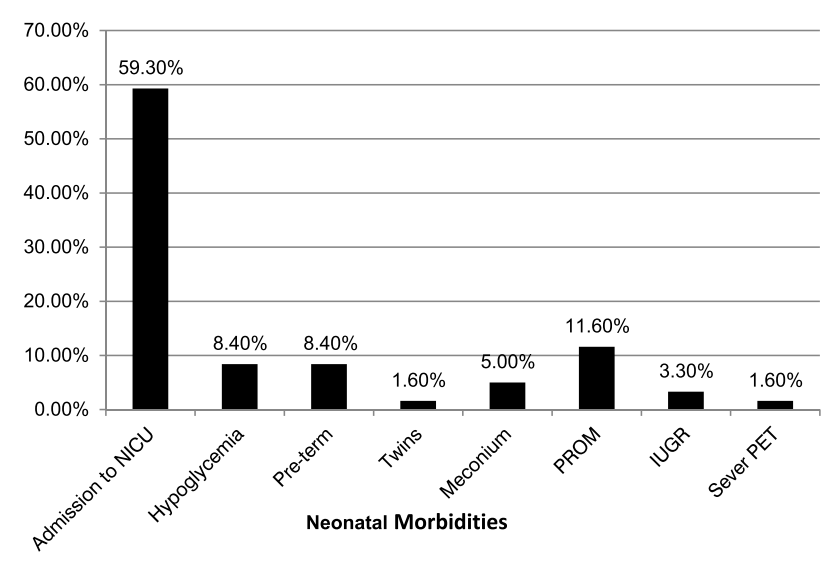

Figure-7

\begin{tabular}{|l|c|c|c|}
\hline \multicolumn{1}{|c|}{ Total } & \multicolumn{1}{c|}{ General $^{*}$} & GDM $^{*}$ & P-Value \\
\hline 2742 & 2512 & 230 & 0.58 \\
\hline hypertension & $106(0.035-0.050)$ & $8(0.017-0.067)$ & 0.982 \\
\hline PPH & $99(0.032-0.047)$ & $9(0.020-0.072)$ & $0.0002^{*}$ \\
\hline induction & $298(0.106-0.131)$ & $88(0.322-0.446)$ & $0.0007^{*}$ \\
\hline Preterm & $229(0.080-0.103)$ & $6(0.012-0.055)$ & 0.211 \\
\hline C-section & $544(0.200-0.233)$ & $58(0.200-0.312)$ & 0.808 \\
\hline macrosomia & $122(0.040-0.057)$ & $12(0.030-0.089)$ & 0.0001 \\
\hline NICU admission & $135(0.045-0.063)$ & $59(0.204-0.316)$ & \\
\hline
\end{tabular}

The induction rate was $38 \%$ which is very high with P-value (.0002) and although the rate of total C-section was not high but those induced before 39 weeks $84 \%$ ended in C-section as shown in Table-III. Regarding C-section rate in this group was $25.2 \%$ and by deducting the previous 2 and $3 \mathrm{C}$-section the corrected rate is $21.8 \%$. Most of the patient induced at $38 \mathrm{wks}$ and ended in C-section for fetal distress $18(62 \%)$, for failure to progress, $7(24 \%)$ and failed IOL 2 (6\%) which is the end result of the cases if induced earlier. The number of prostin used in 19 patients who ended in C-section were as 6(33\%) received 1 dose, $8(39 \%)$ received 2 doses, $2(11 \%)$ received 3 doses, another $2(11 \%)$ received 4 doses and lastly $1(6 \%)$ received 5 doses. Table-IV showed as age increases the incidence of GDM increases. Antenatal complication as shown in Table-V was only $5.3 \%$ much less but the major one was hypertension and polyhydramnios. Post natal complications were the same as in literature but the incidence was only $5.6 \%$ as shown in TableVI. The length of stay among patients who had induction of labour was $2-3$ days in 58(51\%) of patients, 3-5 days in 22(19.3\%) and more than 5 days in $8(7.04 \%)$. The length of stay was longer in patients induced at or before 38 weeks.

\section{DISCUSSION}

The prevalence of GDM has been reported form $1.4 \%$ to $14 \%$ worldwide and different amongst different racial and ethnic groups. The incidence of GDM in King Hamad University Hospital in this study was $8 \%$ whereas prevalence rate of gestational diabetes in kingdom of Saudi Arabia $12.5 \%$ in 2000 , Kingdom of Bahrain $12.5 \%$ in 2001-2002, Malaysia 11\% in 2006,UAE 20.6\%,USA 4.8\%,France $12.1 \%$ and Qatar $8.8 \%$.

Study of GDM in southern Iran showed that BMl of $25 \mathrm{~kg} / \mathrm{m} 2$ or more were prevalent in GDM subject. Study in Jamu region showed significant proportion of subjects with GDM with overweight (19)30.6\% and obese (16)25.8\%.,5,6,8 In our study significant proportion of subjects with GMD 50\% were overweight and $15 \%$ were obese These 
findings confirm that women with greater $\mathrm{BMI}$ are at risk of GMD in pregnancy. . $^{9,10,11,12}$

As the patients with GDM were induced at 38-39 weeks, for analyzing the incidence of vaginal and caesarean births, 230 cases were studied. Among them 170/230 delivered vaginally and 58 cases were delivered by caesarean section constituting $20.8 \%$ of total deliveries. Among vaginal deliveries 103 cases $(46 \%)$ delivered spontaneously and 88 cases $(38 \%)$ were induced. The patients who had IOL 19 cases (21\%) went for C-section. High rate of induction $33-38 \%$ has been reported in the past studies. ${ }^{13,14}$ The $P$ value $(0.0002)$ significant with $95 \% \mathrm{Cl}$ of $298(0.106-0.131)$ in general and In GDM was 88(0.322-0.446).

The preterm delivery was $2.6 \% \mathrm{P}$ value $(.0007)$ with 95\%confidence interval of 229 (.080- 0.131) in general group and 6(0.012-0.055) in GDM group. This is because with good control the incidence in GDM group was low as compared to other group.

The common indication for induction of labor in this study were undelivered at gestation of 39 weeks and somewhere induced earlier at 38 weeks those who were on insulin with $\mathrm{PIH}$ and others presented with rupture of membranes and maternal related causes.

The total number of deliveries by C-Section was $58(25 \%)$. Among them $50 \%$ were elective caesarean section and another $50 \%$ were emergency for different obstetrical reasons. Among emergency cases 19 (33\%) were initially induced. Major cases of emergency C-Section were due to fetal distress $18(62 \%)$, whereas due to failure to progress were7 cases $(21 \%)$ and 2 $(6 \%)$ after failed induction of labor. Lastly previous 2 C-section in labor were 2 (6\%).

Among cases with fetal distress $80 \%$ were initially undergone induction of labor and $10 \%$ followed by spontaneous on set of labor. Amongst patients with failure to progress $67 \%$ was initially induced and $33 \%$ after spontaneous on set of labor.

The study in literature showed high rate of CS in GDM patient despite good maternal control during pregnancy. $8,13,14,15,16$

Our CS rate was $25 \%$ and main indication was fetal distress in labor and previous CS with refusal of trial of scar and CS due to recurrent causes as previous $2 \mathrm{CS}$ or $3 \mathrm{CS}$, if CS done for previous 2or $3 \mathrm{C}$-sections is deducted the total number is 50 and rate is $21.8 \%$ which is matching with other studies like the study conducted in Saudi Arabia, the CS rate was $24.1 \%$. The $p$ value was 0.211 with $95 \% \mathrm{Cl}$ was $54(0.200-0.233)$ in non GDM group and GDM group was 58(0.200-0.089).

Major cases of elective C-Section was due to previous caesarean sections and patients refusing trial of scar 15 (52\% of cases).

Regarding age of the patients $52 \%$ were in the age bracket of $30-40$ Years while $40 \%$ were in the age bracket of 20-30 Years. This is similar to other studies where age more than 25 years is considered as risk factor ${ }^{14,18}$ as study from south India showed age greater than 25 years as the risks factor for GDM. ${ }^{17}$

Out of 230 patients $18 \%$ needed insulin while the remaining $82 \%$ were controlled with diet. This is due to strict diagnostic criteria, education of the patient, dietician and endocrine involvement, patients were self-monitoring at home and more crucially complied with life style modification.

The antenatal complications were seen in 17 patients (7.3\%). The incidence of $\mathrm{PIH}, \mathrm{PET}$ and polyhydramnious was $24 \%$ each, $12 \%$ for obstetric cholestasis and another equal incidence of $1(5.3 \%)$ each for oligohydramnios, hyperthyroidism and heart disorders. The incidence of prematurity was $2.3 \%$ and were induced because of above complications.

In our study, antenatal complication percentage was $7.3 \%$ and among them the major was hypertension related problem due to larger BMI and most of patient they don't know about pre pregnancy blood pressure. The mode of delivery was not much affected, but in literature leads to increase the CS rate. ${ }^{14,18}$ 
Likewise mother with gestational diabetes were 4 times more likely to have hypertension then non-diabetes. The $\mathrm{p}$ value was 0.58 with $\mathrm{Cl}$ in general group 106(.035-0.050) and in GDM group 8(.017-0.067). The risk factor of GDM and obesity predispose them to hypertension as shown in this study. The hypertensive disorders leads to placental insufficiency and intrauterine growth restriction and increase in perinatal morbidity and mortality. ${ }^{19}$

In total post natal complications rate was (5.6\%) in13 cases. Primary Postpartum Haemorrhage was seen in 7 cases (54\%) followed by an equal incidence of (2) $15 \%$ for perinatal tears sutured under GA and (2) $15 \%$ for wound infections. The manual removal of placenta (1) and evacuation of hematoma (1) were seen in (8\%) patient each. The Pvalue was 0.982 with a $95 \% \mathrm{CL}$ of $99(.032-.047)$ in general and 9(0.020_0.072) in GDM group. The maternal morbidity because of increase tissue trauma, $\mathrm{PPH}$, lacerations could be because of affected tissues and vessels in GDM patients with underlying pathology and needs further research. One of the study in kingdom of Saudi Arabia with 972 GMD cases showed common complications as perineal-tears in $18 \%$ of cases as a reason for primary postpartum hemorrhage. ${ }^{20}$

The average baby weight was $3-3.9 \mathrm{~kg}$ with an incidence of $58 \%$ followed by $34 \%$ of the babies born between $2.5-3 \mathrm{~kg}$ and $3.4 \%$ weighing 4-4.5kg. ${ }^{18}$ Among the patients few unbooked patients attending the hospital late with poorly controlled or undiagnosed status. They had OGTT for the diagnosis of diabetic status.

The aim of control is to reduce the risk of macrosomia. In our study most of the babies were average weight showing good control. Only 6 patients in range of $4-4.4 \mathrm{~kg}$ and 1 patient for 4.5 $\mathrm{kg}$ which constituted only $3 \%$ of total deliveries with a Pvalue of 0.808 and $95 \% \mathrm{Cl} 122$ (.040.057)for general population and 12(.030-.089) GDM patients. There was no shoulder dystocia. Although most of our patients were induced between 38-39 weeks could be the reason but Cochrane does not support. ${ }^{18}$
Control of GDM can reduce perinatal morbidity and mortality, the studies have shown the serious perinatal morbidity can be reduced with treatment of mothers with GDM. ${ }^{21,22,23}$

Many randomized control studies proved that treating with mildest form of GDM can reduce complications and birth trauma as well as antenatal complications. ${ }^{24,25}$

NICU admission was seen in 59 cases $25.7 \%$ more than mentioned in literature. Among them $58.3 \%(35)$ babies were admitted due to routine observation for $24 \mathrm{hrs}$ in babies with GMD mothers. The rest were due to hypoglycemia, prematurity, meconium aspiration, pre mature rupture of membranes and intrauterine growth restriction. ${ }^{26}$ But if we review all this there was no perinatal mortality or severe morbidity. Only $3.4 \%$ of the babies were $4-4.5 \mathrm{~kg}$ and we did not come across any shoulder dystocia, poor Apgarscore, still-birth or respiratory distress syndrome. Complications were not encountered because the study was conducted in hospital with proper follow up and excellent care. ${ }^{27} \mathrm{NICU}$ admissions total 59 (25.7\%) $P$ value .00001 . This percentage is more than in studies in literature which are $4.5 \_10 \%$. The protocol of our NICU department was to admit all the GDM babies whose mother were on insulin and they were kept there for two readings. If readings were fine and baby was feeding they were discharged to postnatal nursery. The places where NICU admission was low they were using the admission criteria for admitting the babies to NICU. Since it was at the start of new hospital and staffing problem at postnatal ward. By adequate staffing and following the criteria to admit to NICU we can certainly reduce our NICU admissions. ${ }^{27}$

The length of stay was more in patients started induction at 37-38 weeks due to poor bishop and less chance of spontaneous onset of labour because of early intervention. ${ }^{27}$ In our study from 18 patient of induction of labour that went for C-section 16 were less than 39 weeks.

This study proved that well controlled diabetes with good compliance, no interventions in the absence of any other risk factor increases the 
incidence of vaginal birth. In our study the patients who were conservatively managed until 39-40 weeks the incidence of induction was reduced and so the incidence of $\mathrm{C}$-section. ${ }^{27}$

\section{CONCLUSION}

- This study proves the advantage of adhering to the IADPSG criteria in diagnosing and management of the gestational diabetes mellitus for significantly positive effect in pregnancy outcome in relations to mother and child.

- In our opinion this strategy was good as we started controlling patients sugar levels earlier in pregnancy as most of GDM patients are with larger BMI.

- The education about weight management before embarking on pregnancy and to complete family in earlier rather than late age could be the next step for better outcome.

- The role of aspirin in selected cases can be useful for prophylaxis against hypertension.

- The GDM will continue to pause problem as obesity is increasing throughout the world. A step forward will be education about life style, maintenance of weight, healthy diet, pre pregnancy counseling and assessment to avoid the diabetic complications.

\section{LIMITATIONS}

Because the study was conducted from the time the hospital was getting started and new computer system was introduced. The data and some of the information was missing so there was difficulty in collecting information, e.g. weight of mother and weight of babies. Some of the patients were labelled as GDM but when investigated were not.

\section{ACKNOWLEDGEMENTS}

Thanks to Dr Gulmeen Raza for helping specifically in premise of study and statistics. Dr Sara and Shereen for collecting the data and helping in statistics.

Copyright@ 11 June, 2019.

\section{REFERENCES}

1. Antenatal care: Routine care for the healthy pregnant woman. NICE clinical guideline 62 (2008). Available from www.nice.org.uk/CG062.
2. Sella $T^{1}$, Shalev V, Elchalal U, Chovel-Sella A, Chodick Screening for gestational diabetes in the 21st century: a population-based cohort study in Israel. J Matern Fetal Neonatal Med. 2013 Mar; 26(4):412-6. doi: 10.3109/14767058.2012.733761. Epub 2012 Oct 30.

3. Malak M. Al-Hakeem, ABOG; Pregnancy outcome of gestational diabetic mothers: Experience in a Tertiary Center. Family Community Med. 2006 May-Aug; 13(2): 55-59. PMCID: PMC341006

4. Metzger BE, Gabbe SG, Persson B, Buchanan TA, Catalano PA, Damm P, Dyer AR, Leiva A, Hod M, Kitzmiler $\mathrm{JL}$, et al: International association of diabetes and pregnancy study groups recommendations on the diagnosis and classification of hyperglycemia in pregnancy. Diabetes Care 2010, 33:676-682.6 Viechtbauer W: Conducting Meta-Analyses in R with the metaphor Package. J Stat Software 2010, 36:1-48.

5. Amy Shah, M.D., ${ }^{1}$ Naomi E. Stotland, M.D., ${ }^{2}$ Yvonne W. Cheng, M.D., M.P.H., ${ }^{2}$ Gladys A. Ramos, M.D., ${ }^{3}$ and Aaron B. Caughey, M.D., Ph.D. The Association between body mass index and gestational diabetes mellitus varies by race/ethnicity. Am J Perinatol. 2011 Aug; 28(7): 515-520.

6. Farzad Hadaegh, Maryam Tohidi, Hadi Harati, Maryam Kheirandish, and Shafei Rahimi (2005) Prevalence of gestational diabetes mellitus in southern Iran (bandar abbas city). Endocrine Practice: September 2005, Vol. 11, No. 5, pp. 313-318.

7. Seshiah V, Balaji V, Balaji MS et al. Prevalence of gestational diabetes mellitus in South India (Tamil Nadu) - a community based study. J Assoc Physicians India 2008; 56:329-333.

8. Dornhost A, Pateson EM, Nicholls JSD, et al. High Prevalence of GDM in women from ethnic minority groups. Diabetic Medicine. 1992; 9:820-825. [PubMed]

9. King $\mathrm{H}$. Epidemiology of glucose intolerance and GDM in woman of child bearing age. Diabetes Care. 1998; 21 (Suppll. 2):B9-13. [PubMed]

10. Khaundelwal M, Homko C, Reece EA. Gestational diabetes mellitus: Controversial and current opinion. Current opinion Obstet Gynaecol. 1999; 11(2):157-165.

11. Xiong $X$, Saunders LD, Wang FL, Demianczuk NN. Gestational diabetes mellitus: Prevalence, risk factors, maternal and infant outcomes. Int J Gynaecol Obstet 2001. Dec;75(3):221-28 10.1016/S00207292(01)00496-9 [PubMed] [Cross Ref]

12. Siribaddana SH, Deshabandu R, Rajapakse D, et al. The Prevalence of GDM in Sri Lankan antenatal clinic. Ceylon-Med-J. 1998; 43(2):88-91. [PubMed] 
13. Peticca P, Keely EJ, Walker MC, Yang Q, Bottomley J. Pregnancy outcomes in diabetes subtypes: how do they compare? A province-based study of Ontario, 2005-2006. J Obstet Gynaecol Can 2009 Jun; 31 (6):48796.

14. Tan PC, Ling LP, Omar SZ. The 50 -g glucose challenge test and pregnancy outcome in a multiethnic Asian population at high risk for gestational diabetes. Int $\mathrm{J}$ Gynaecol Obstet 2009 Apr; 105(1):50-55

15. Bancrofti K, Tuffnel GC, Mason, et al. A randomized controlled pilot study for the management of gestational impaired glucose tolerance. BJOG. 2000; 107:959-63. [PubMed]

16. Scott-Pillai R, Spence D, Cardwell CR, Hunter A, Holmes $V A$. The impact of body mass index on maternal and neonatal outcomes: $A$ retrospective study in UK Obstetric population. BJOG 2013 http://dx.doi. org/10.1111/1471-0528.12193.]

17. Susan Y. Chu et al. Maternal obesity and risk of gestational diabetes mellitus institute for clinical research and health policy studies, Tufts-New England Medical Center, Boston, Massachusetts Diabetes Care 2007 Aug; 30(8): 2070-76. http://dx.doi. org/10.2337/dc06-2559a

18. Naylor CD Naylor CD, Sermer M, Chen E, Sykora $K$. Caesarian delivery in relation to birth weight and glucose gestational tolerance. JAMA. 1996; 275(15):1164-70. [PubMed\}

19. Jensen DM, Sorensen B, Feilberg-Jorgensen $\mathrm{N}$, Westgaard JG, Beck Neilsen $H$. Maternal and perinatal outcome in143 Danish women with GDM as compared to 143 nondiabete with a similar risk profile. Diabet Med 2000 April:17(4); 281-86.

20. K.O. El Mallah, H. Narchi, N.A. Kulaylat, M.S. Shaban. Gestational and pre-gestational diabetes: Comparison of maternal and fetal characteristics and outcome. International journal of obstetrics and gynecology. Volume 58, Issue 2, August 1997, Pages 203-9
21. Johns K, Olynik C, Mase R, Kreisman S, Tildesley $\mathrm{H}$. Gestational diabetes mellitus outcome in 394 patients. J Obstet Gynaecol Can 2006. Feb; 28(2):12227 [PubMed]

22. Crowther CA, Hiller JE, Moss JR, McPhee AJ, Jeffries WS, Robinson JS, Australian carbohydrate intolerance study in pregnant women (ACHOIS) trial group effect of treatment of gestational diabetes mellitus on pregnancy outcomes. N Engl J Med 2005. Jun; 352(24):2477-86 10.1056/NEJMoa042973 [PubMed]

23. Zera $\mathrm{CA}^{1}$, Seely EW Diabetes: Treatment of gestational diabetes reduces obstetric morbidity Nat Rev Endocrinol. 2010 Feb; 6(2):69-70. doi: 10.1038/ nrendo.2009.265

24. Bonomo M, Corica D, Mion E, Gonçalves D, Motta G, Merati $R$, et al. Evaluating the therapeutic approach in pregnancies complicated by borderline glucose intolerance: A randomized clinical trial. Diabet Med 2005. Nov; 22(11):1536-41 10.1111/j.14645491.2005.01690.x [PubMed] [Cross Ref]

25. Landon MB, Spong CY, Thom E, Carpenter MW, Ramin SM, Casey B, et al. Eunice Kennedy Shriver national institute of child health and human development maternal-fetal medicine units network A multicenter, randomized trial of treatment for mild gestational diabetes. N Engl J Med 2009. Oct; 361(14):1339-48 10.1056/NEJMoa0902430 [PMC free article] [PubMed]

26. Ostlund I, Hanson U, Björklund A, Hjertberg R, Eva $\mathrm{N}$, Nordlander $\mathrm{E}$, et al. Maternal and fetal outcomes if gestational impaired glucose tolerance is not treated. Diabetes Care 2003. Jul; 26(7):2107-11 10.2337/diacare.26.7.2107 [PubMed] [Cross Ref].

27. Gasim T. Gestational diabetes mellitus: Maternal and perinatal outcome in 220 Saudi women. Oman Med J 2012 Mar; 27(2):140-14.

\begin{tabular}{|c|l|l|l|}
\hline \multicolumn{3}{|c}{ AUTHORSHIP AND CONTRIBUTION DECLARATION } \\
\hline Sr. \# & \multicolumn{1}{|c|}{ Author-s Full Name } & Contribution to the paper & Author=s Signature \\
\hline 1 & Samina Anwar & Main author & \\
\hline 2 & Gulmeen & Co-author \\
\hline 3 & Shareen Sultan & Data collection and graphs & \\
\hline 4 & Sara Amin & Data collection and graphs & \\
\hline
\end{tabular}

